\title{
Design and Application of a Multichannel Analysis Surface Waves Acquisition System for the Pavement Layers Investigation
}

\author{
Cheikh Diallo Diene, Mapathé Ndiaye \\ Laboratory of Mechanics and Modeling, University of Thiès, Thiès, Senegal \\ Email: cheikhdialo.diene@univ-thies.sn
}

How to cite this paper: Diene, C.D. and Ndiaye, M. (2022) Design and Application of a Multichannel Analysis Surface Waves Acquisition System for the Pavement Layers Investigation. Open Journal of Civil Engineering, 12, 22-37.

https://doi.org/10.4236/ojce.2022.121003

Received: December 18, 2021

Accepted: January 23, 2022

Published: January 26, 2022

Copyright $\odot 2022$ by author(s) and Scientific Research Publishing Inc. This work is licensed under the Creative Commons Attribution International License (CC BY 4.0).

http://creativecommons.org/licenses/by/4.0/

\begin{abstract}
This study aims to design and develop a pavement non-destructive quality testing device with the MASW method. Unlike the traditional acquisition techniques that plants geophones on the pavement, the presented approach uses no-tip geophones, placed directly on the pavement surface to preserve its integrity. To proceed, a seismograph using an Arduino Due microcontroller connected to a Raspberry Pi 4 nano-computer was developed. The receivers consist of $64.5 \mathrm{~Hz}$ GD geophones connected together by a graduated tape to control the inter-trace distance and to in order to acquire data in land-streamer. The recording is triggered by a KY-038 sound sensor. The Arduino acts as an analog-to-digital converter while the Raspberry is used as a real-time data visualization and processing interface. The obtained seismic data has been processed using the Geopsy open-source software which allows the analysis and inversion of the dispersion curves. The studied system has been tested in 4 different sites. The obtained seismic $V_{S}$ and $V_{P}$ velocities as a function of the depth allowed to deduce the elastic properties of the pavement layers and to decide on their mechanical quality with the possibility of integrating the results in the road data banks.
\end{abstract}

\section{Keywords}

Survey, Road, Elastic Properties, MASW, Arduino, Raspberry, Geophone

\section{Introduction}

Premature pavement degradation is attributed various factors like poor quality road materials, inadequate handling environmental conditions, construction or even operating conditions [1]. Quality control is very important for planning of 
preventive maintenance in order to extend their service life. One common way of proceeding is to follow the evolution of the mechanical properties of pavement layers such as Young modulus, shear modulus, compressibility modulus, the Lame ratios, density and Poisson ratio, etc. Several in situ or laboratory geotechnical tests allow us to determine the mechanical properties with a certain precision [2] [3].

Besides geotechnical methods that are invasive, there are indirect methods used in geophysics to determine mechanical properties. Seismic methods are still widely used in this way, because of the relationship between the velocity of different types of seismic waves and elastic properties [4] [5].

Typically, in seismic survey, volume waves ( $\mathrm{P}$ and $\mathrm{S}$ waves) are used, and surface waves ( $R$ and $L$ waves) are considered as noise. As a result, very often, it is possible to try to reduce the effect of surface waves either by filtering during the acquisition, or by using signal processing methods. However, just like volume waves, surface waves provide information about elastic properties of the crossed terrain. Moreover, they were used for a long time in seismology to study the internal structure of the Earth, [6]. Also, it is established that the greatest proportion of the energy of a surface seismic source is made up of surface waves (67\%), compared to volume waves which make up only $7 \%$ and $26 \%$ respectively for $\mathrm{P}$ and $\mathrm{S}$ waves [7].

The surface wave inversion method makes it possible to know the mechanical properties of a shallow elastic medium [8] [9]. It proceeds by analyzing the propagation of surface waves. From the 1960s, surface waves were used empirically to study the structure of pavements by comparing surface wave dispersion curves on pavements with theoretical dispersion curves [10] [11]. The technique was constantly improved afterwards. Examples include Continuous Surface Waves [12], Spectral Analysis of Surface Waves [13], Multichannel Analysis of Surface Waves [14] or Multichannel Simulation with One Receiver [15].

However, the use of surface waves as a method of pavements investigation remains tedious due to the difficulty of implanting geophones on the pavement. In addition, the used bulky devices make the implementation more complicated and longer on an in-service road. The aim of this work is on the one hand, to develop a lighter system, less bulky and suitable for roads even in service and on the other hand to bypass the difficulties of implantation by using as control unit a coupling of Arduino Due type microcontrollers with a Raspberry Pi type nano-computer for greater handling flexibility and for cost effectiveness. The receivers consist of $4.5 \mathrm{~Hz}$ GD geophones directly placed on the pavement surface.

In this article, the first step is to address some theoretical aspects of surface waves and their use for road layers testing before moving to the design and testing of the device developed through a case study.

\section{Material and Method}

From the 1960s, surface waves were used empirically to study pavements struc- 
ture by comparing surface wave dispersion curves on pavements with theoretical dispersion curves [16]. The technique was constantly improved afterwards. An example is Spectral Analysis of Surface Waves (SASW) method [13], which uses two geophones connected to a spectrum analyzer, Continuous Surface Waves method [12], Multichannel Simulation with One Receiver (MSOR) method [15] or the Multichannel Analysis of Surface Waves method [14].

The Multichannel Analysis of Surface Waves (MASW) method investigates a shallow environment [17]. It uses an active source. The equivalent method using a passive source is the Refraction Microtremor (ReMi) method [18]. As an alternative to MASW, there is the Multichannel Simulation with One-Receiver (MSOR) method [19] [20]. In the MSOR method, the source and receiver roles are reversed based on the reciprocity theorem in Mechanics.

The principle of MASW is first to acquire distance-time signals using the same device as in refraction seismic [21] [22]. Data acquisition is performed using low frequency geophones, aligned and vertically planted on a straight line representing the geometric profile. The acquisition takes into account the offset, the inter-trace distance, the number of geophones and the total length of the device.

The number of geophones $(\mathrm{N})$ required for MASW surveys is generally estimated to be 12 or more. Typically, 24, 48 or 64 receivers are used for data acquisition [9]. The offset $x_{1}$ is the distance between the point of impact and the first receiver. To avoid the adverse effects of the near field, that is, the risk that geophones will pick up the nonplanar surface waves, can be minimized by a judicious choice of $x_{1}$ [22]. The distance between the receivers $(d x)$ is related to the shortest wavelength that can be included in a dispersion curve $d x \leq 0.5 \lambda_{\min }$. The depth of investigation $\left(z_{\max }\right)$ is determined by the longest Rayleigh wavelength obtained during data acquisition $\left(\lambda_{\max }\right)$. One commonly adopted empirical criterion is:

$$
Z_{\text {max }} \approx 0.5 \lambda_{\text {max }}[22]
$$

The work of Park (2002) allowed through simulation, to establish a table facilitating the choice of an acquisition geometry according to the targeted resolution and depth.

In a second step, a FK analysis is applied to the distance/time data to extract the Rayleigh wave dispersion. Dispersion is the consequence of the difference in propagation speed of the different frequencies of the surface waves [23].

In general, two approaches can be used for dispersion analysis: the swept frequency approach [14], and the phase shift method [24]. In this article, the phase shift method which can be divided into 7 main steps was treated.

A Fast Fourier Transform (FFT) is applied to each recorded trace to transform the time record into frequency components.

$$
u_{j}(t) \stackrel{\mathrm{FFT}}{\longrightarrow} \tilde{u}_{j}(\omega)
$$

Transformed signal amplitudes are: 


$$
\tilde{u}(\omega)=\tilde{u}(\omega) /|\tilde{u}(\omega)|=P_{j}(\omega)
$$

As $\tilde{u}(\omega)$ and $P_{j}(\omega)$ contains all information about its dispersion properties, no significant information is lost.

Thereafter, a phase velocity interval to be processed is established as follows:

$$
V_{\text {min }} \leq V_{\text {test }} \leq V_{\text {max }}
$$

For each given couple $\left(\omega ; V_{\text {test }}\right)$, the required phase shift is determined in order to compensate for the corresponding time delay.

$$
\phi_{\text {test }}=\omega x_{j}
$$

The obtained amplitudes are summed:

$$
A\left(\omega ; V_{\text {test }}\right)=\mathrm{e}^{-i \phi_{\text {test }} x_{1}} \tilde{u}_{1, \text { norm }}(\omega)+\cdots+\mathrm{e}^{-i \phi_{\text {lest }} x_{N}} \tilde{u}_{N, \text { norm }}(\omega)
$$

The previous 2 steps are repeated for different values de $\omega$ et $V_{\text {test }}$.

The dispersion curve is obtained by plotting the summed amplitude in the frequency-velocity phase domain. The observed amplitude peaks show the dispersion characteristics of the recorded surface waves.

The last step corresponds to the inversion of the dispersion curve. It is done by a priori estimation of the intervals for the parameters of the model: thickness of the layers, shear waves velocity $V_{S}$ compression waves velocity $V_{P}$ Poisson ratio and the density of each layer.

The theoretical dispersion curves are iteratively computed using the Kausel and Roësset (1981) stability matrix method for various sets of model parameters. At each iteration, the theoretical dispersion curve is calculated for the wavelengths included in the experimental dispersion curve, i.e., $\lambda_{t, q}=\lambda_{e, q}$.

The error between the experimental and theoretical dispersion curves is estimated at each iteration. All the initial parameters of the model are used to calculate the theoretical velocity phase of Rayleigh wave $c_{t, q}(q=1, \cdots, Q)$ corresponding to each wavelength

$$
\lambda_{t, q}=\lambda_{e, q} .
$$

The offset between the theoretical dispersion curve and the observed experimental curve is then evaluated according to the RMS between the theoretical and experimental phase velocity of Rayleigh

$$
\varepsilon=\sqrt{\frac{1}{Q} \sum_{q=1}^{Q}\left(c_{t, q}-c_{e, q}\right)^{2}}
$$

Convergence is considered when the error becomes very small $(<5 \%)$, or when RMS changes is negligible between two iteration. The different steps from the acquisition to the velocity distribution model $V_{S}$ and $V_{P}$ are shown in Figure 1.

In order to acquire surface waves propagation data on a pavement, a device suitable for road investigations have been designed, especially those in service. The seismograph consists of an Arduino Due [25] microcontroller connected using Serial interface with a Raspberry pi 4 nano-computer [26]. The Arduino Due is equipped with an Atmel SAM3X8E ARM Cortex-M3 processor and an 84 


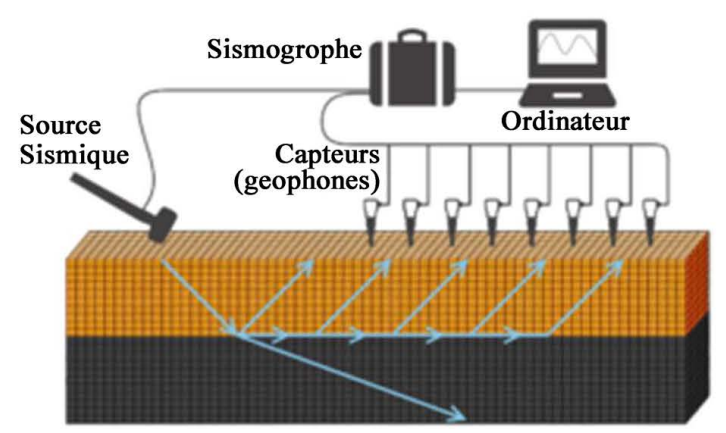

1. Field Acquisition

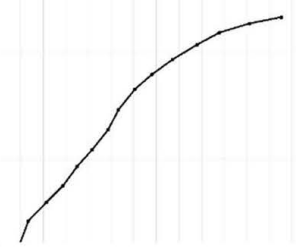

4. Picking Dispersion curve

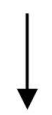

6. Theorical and experimental dispersion curve superposition

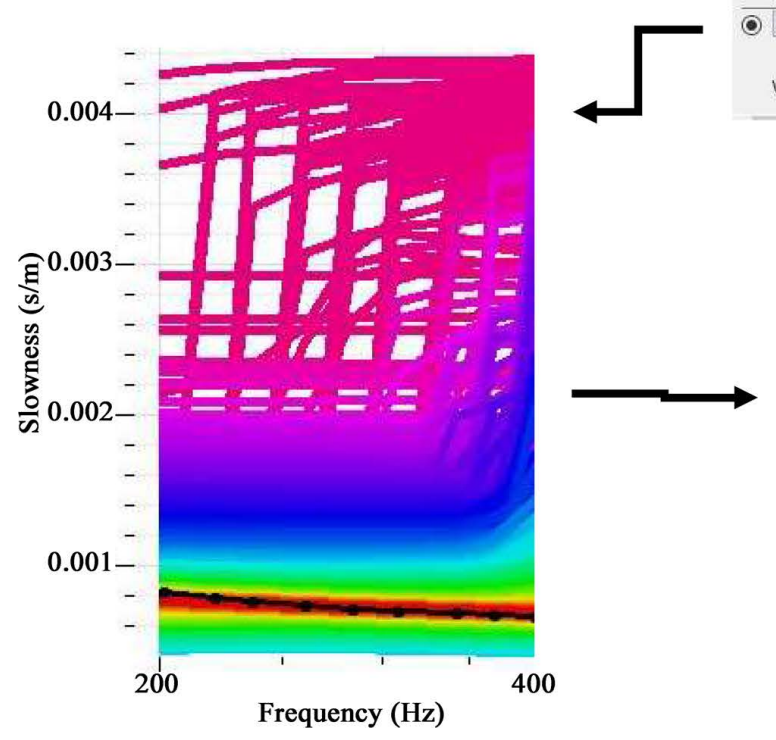

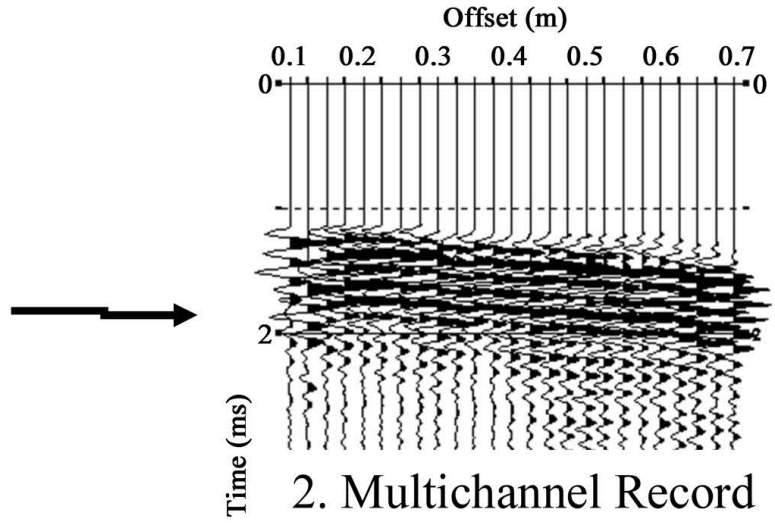

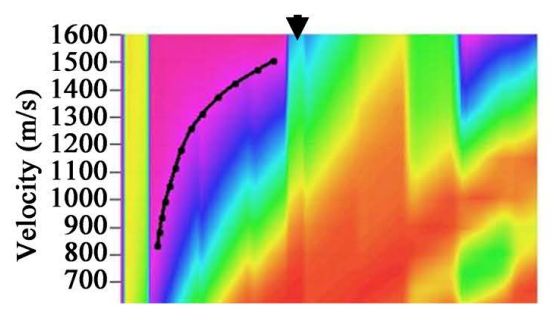

3. Dispersion Imaging
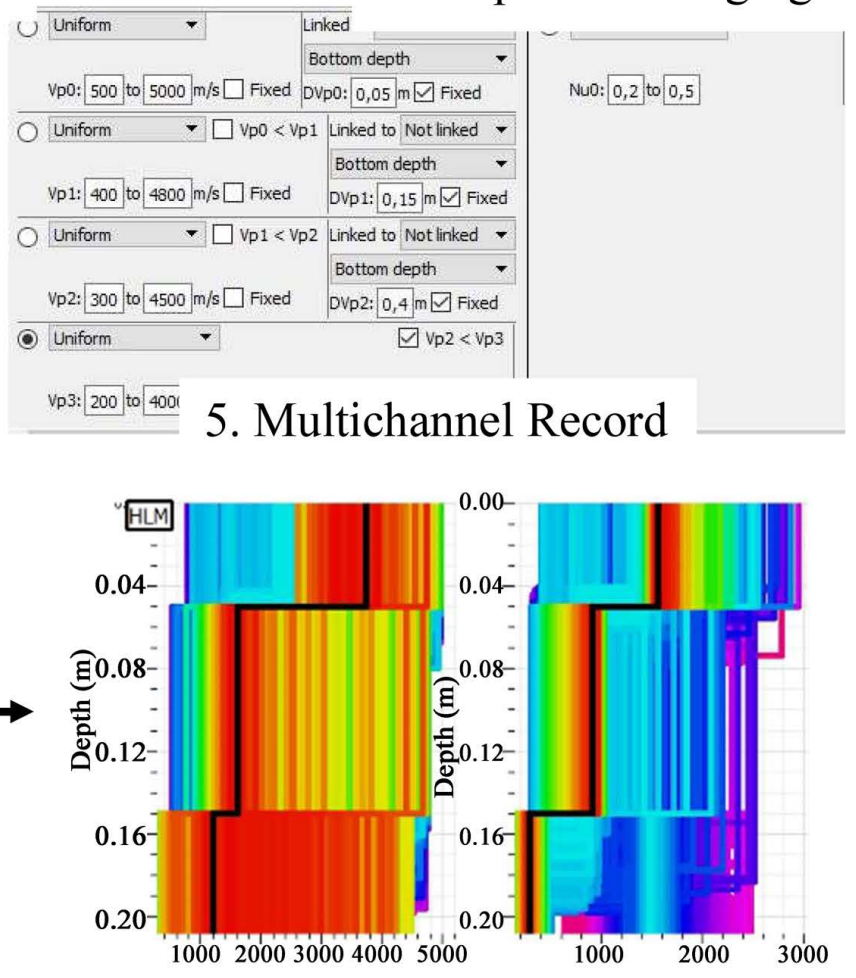

7. Vs and Vp profile

Figure 1. The main steps of a phase-shift method.

$\mathrm{MHz}$ clock making it the fastest microcontroller in its group. It is equipped with a digital analog converter which despite its 10-bit resolution can sample on 12 channels at a frequency of $0.02 \mathrm{~ms}$. The 10-bit resolution, even if it is below that of conventional seismographs makes it possible to acquire seismic data with suf- 
ficient precision for MASW prospecting.

Data from the Arduino Due are sent to the Raspberry Pi 4 by the Serial port. The Raspberry has a python program that allows stacking, displaying and saving data in XML and SEGY formats for further processing.

The recording is triggered by a KY037 sound sensor. The sensor detects the impact of the shot and orders the start of the measurements which must be simultaneous so as not to miss the measurement window. A 7 inch LCD screen connected in HDMI to the Raspberry allows to view the raw data for assessment by the operator before validation. This designed device is in an embedded system, powered by rechargeable lithium batteries to guarantee its autonomy for use in the field (Figure 2).

The active seismic source consists of a $1 \mathrm{~kg}$ hammer and the receivers consist of 6 GD geophones. The ZF-4.5 Hz model uniaxial sensor from Zhaofeng Geophysical was selected [27]. In general, geophones are often equipped with steel tip that ensures their implantation and solidarization with the ground, but in this specific case since it is an investigation on a road, the lower flat base of the geophone is laid on the road.

In order to test the present device, 4 different sites were selected (see Table 1, Figure 3)

In the MASW method, a number of 24 geophones is trade-off between data quality and effectiveness. However to keep the ease of handling, the spread line is limited to 6 geophones. To obtain 24 tracks, the MSOR method is simulated with offset shots for times on fixed impact point. At each shot the geophones are moved simultaneously, keeping the same inter-trace-distance of $10 \mathrm{~cm}$. Some details on the acquisition parameters are presented in Table 2.

For convenience with geophones without spikes on the road, this displacement of a portion of the profile will be done in land-streamer mode [28] using a graduated ribbon that will ensure the inter-trace distance (see figure).

The data from the Arduino are in XML format. Using the Obspy library [29], the XML file is converted to SEGY format. SEGY data is analyzed with Open Source Geopsy Software [30]. Geopsy allows introducing the geometry, performing the dispersion curves analysis and inversion.

\section{Results and Discussion}

The figures below show the raw data obtained at the 4 investigated sites (Figure 4).

After the introduction of the geometry of the data, a linear FK analysis is performed with velocity and frequency ranges in the interval $[0,1600]$ and $[0,2000]$ respectively. A linear sampling interval of 100 is applied both in velocity and frequency. The dispersion curves below are obtained for the different sites (Figure 5).

The dispersion analysis covers a wide range of frequencies and shows all surface wave propagation modes (Figure 5). 


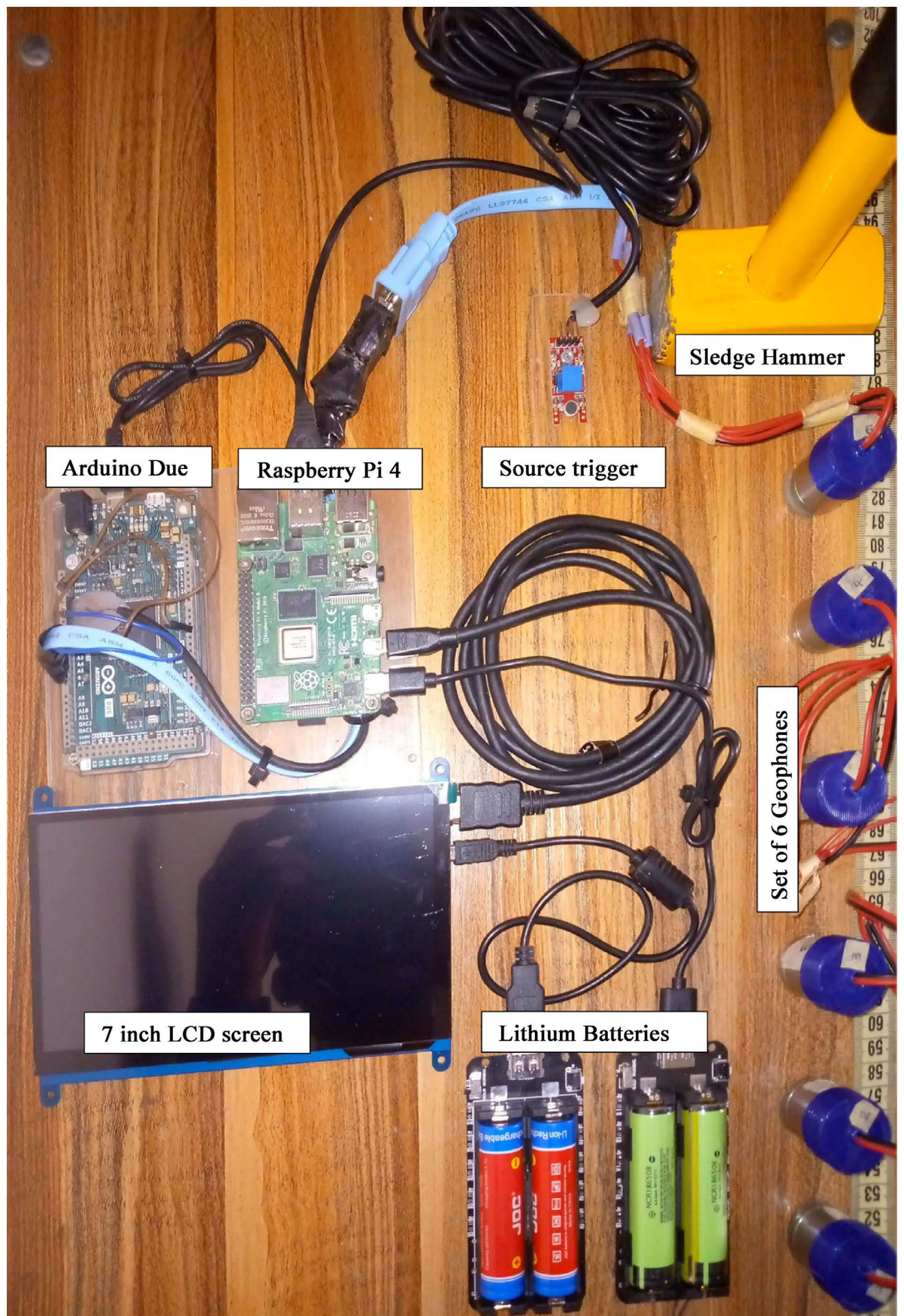

Figure 2. MASW acquisition system.

Table 1. UTM coordinates of the different sites.

\begin{tabular}{cccc}
\hline Sites & X UTM $(\mathrm{m})$ & Y UTM $(\mathrm{m})$ & Name \\
\hline 1 & 292,528 & $1,635,965$ & Auditorium \\
2 & $2,913,411$ & $1,636,005$ & CNEPS \\
3 & 291,723 & $1,635,664$ & HLM \\
4 & 291,548 & $1,635,429$ & Gendarmerie \\
\hline
\end{tabular}




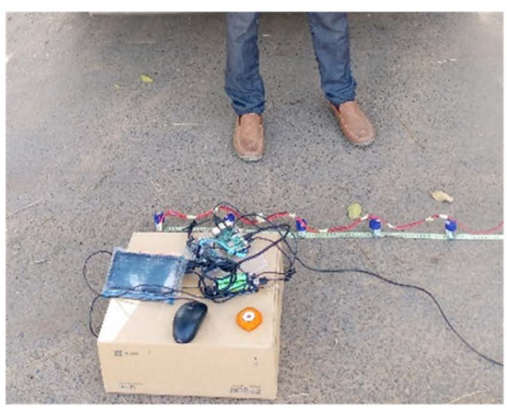

(a)

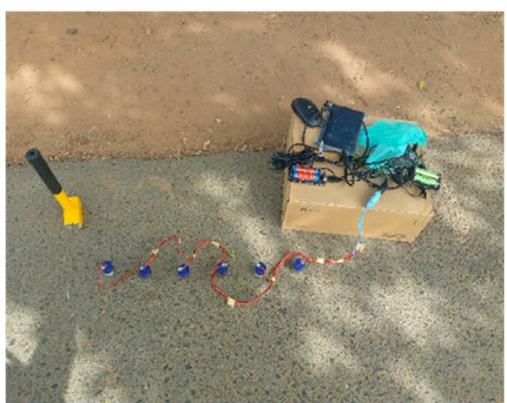

(c)

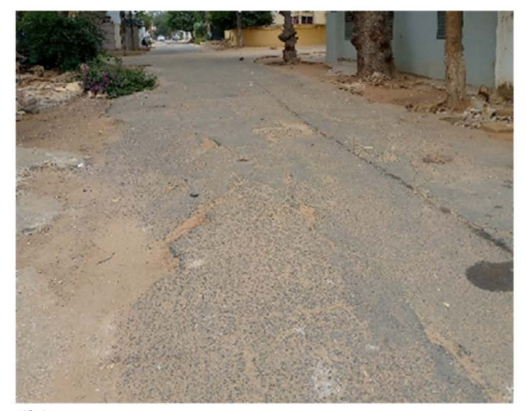

(b)

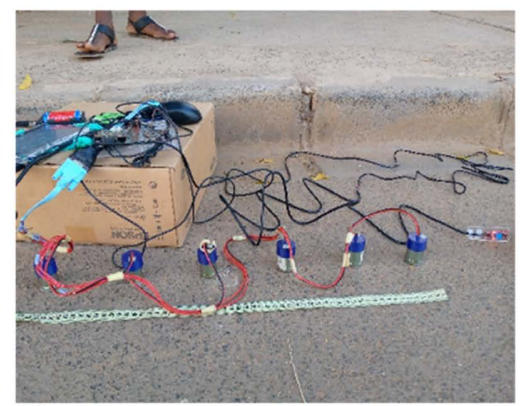

(d)

Figure 3. The different investigated sites: Auditorium (a), HLM (b), Gendarmerie (c) and CNEPS (d).

Table 2. Acquisition parameters.

\begin{tabular}{cc}
\hline Source & Marteau de $\mathbf{~ K g}$ \\
\hline Offset & $0.5 \mathrm{~m}$ \\
Distance between geophones & $0.1 \mathrm{~m}$ \\
Number of Geophones & 6 \\
Sampling interval & $4.10-6 \mathrm{~s}$ \\
Measurement time & $0.008 \mathrm{~s}$ \\
Number of samples & 2000 \\
Sampling frequency & 250,000 \\
\hline
\end{tabular}

Simulation results on pavement layers by Nils (2004) confirmed that the fundamental mode of the dispersion curve occurs over the $0-400 \mathrm{~Hz}$ frequency range. This interval was also confirmed by Park (2018), who pointed out that the frequency band of occurrence of the fundamental mode on the dispersion curve is dependent on the profile length and the geophones spread. This has been confirmed on the various test sites which show a dispersion curve with the fundamental mode in the frequencies from 0 to $400 \mathrm{~Hz}$. For easy picking of dispersion, dispersion curves were limited to $0-400 \mathrm{~Hz}$ to increase resolution as shown in Figure 6.

All the four curves show that dispersion is reversed compared to a normal situation where low frequencies propagate at higher velocities. This reversal can be explained by the decrease in velocities with the depth on pavements. Indeed, 


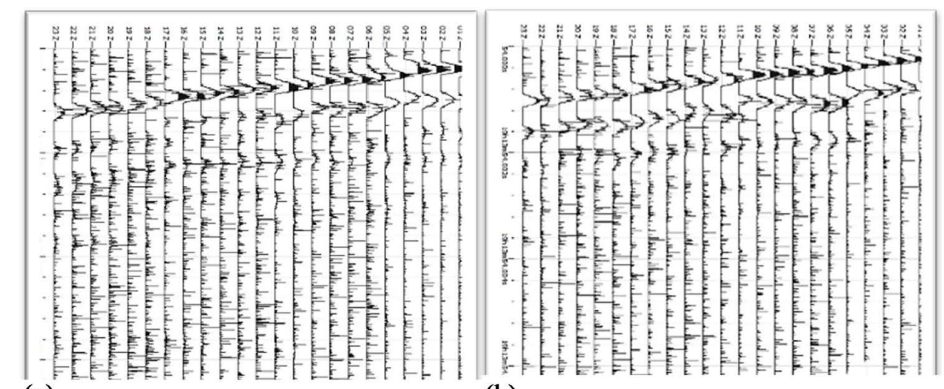

(a)

(b)

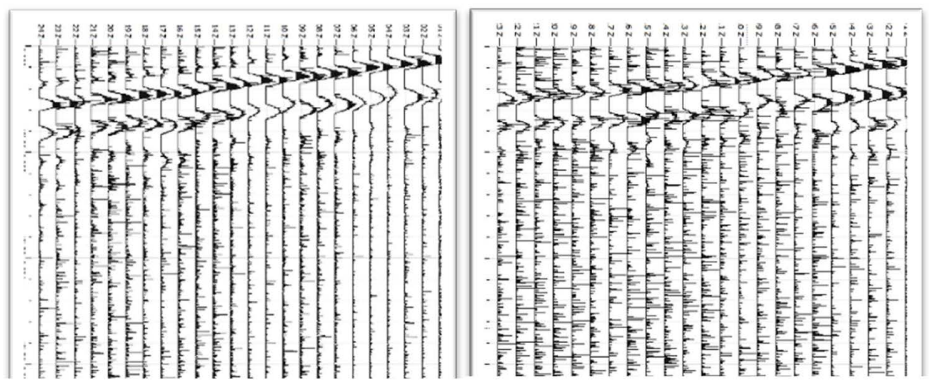

(c)

(d)

Figure 4. Seismograms obtained for Auditorium (a), CNEPS (b), HLM (c) and, Gendarmerie (d).
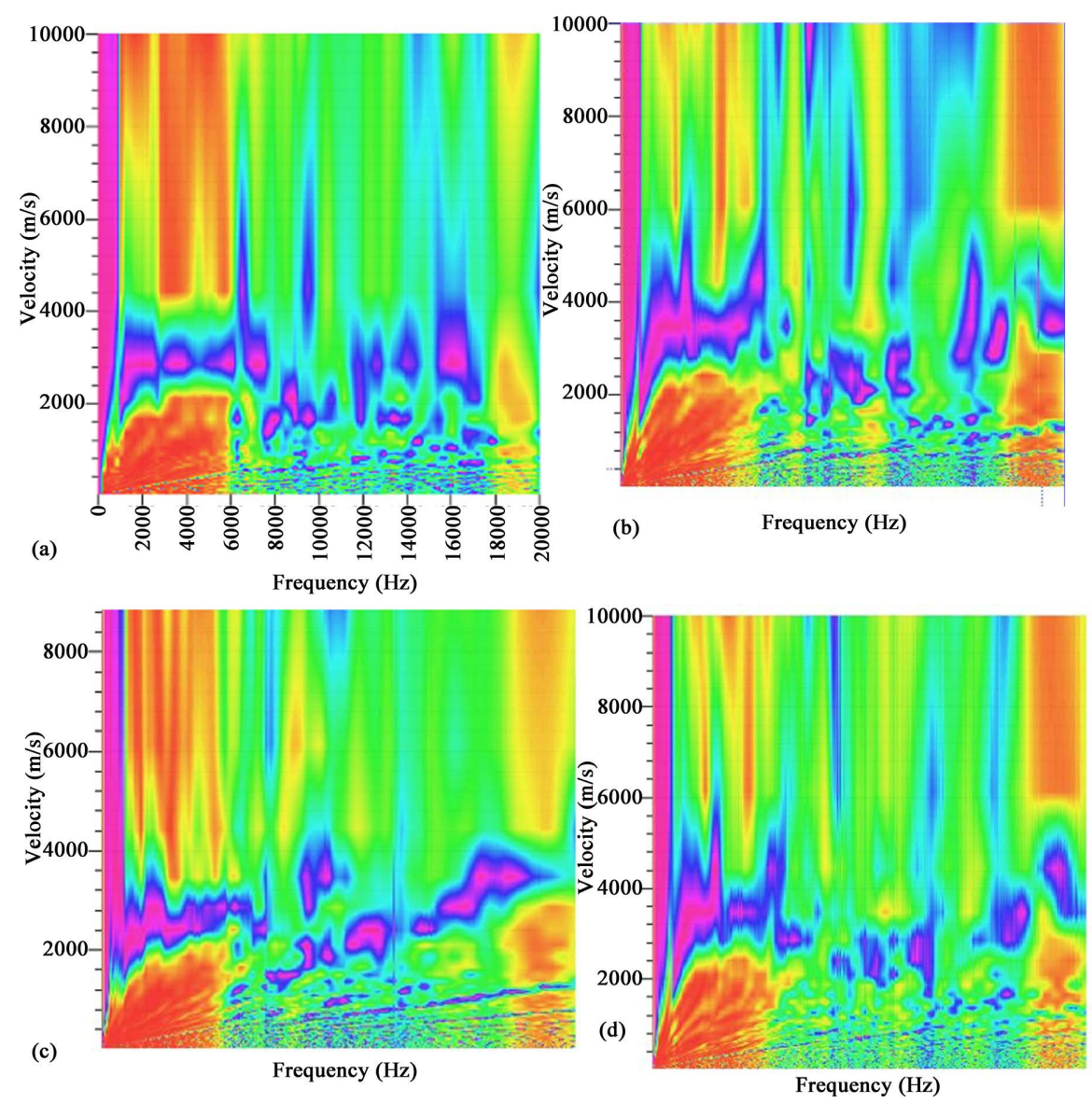

Figure 5. Imagery on a frequency band of $0-20,000 \mathrm{~Hz}$ and speeds of $0-10,000 \mathrm{~m} / \mathrm{s} \mathrm{ob}-$ tained for the Auditorium (a), CNEPS (b), HLM (c) and Gendarmerie (d) sites. 

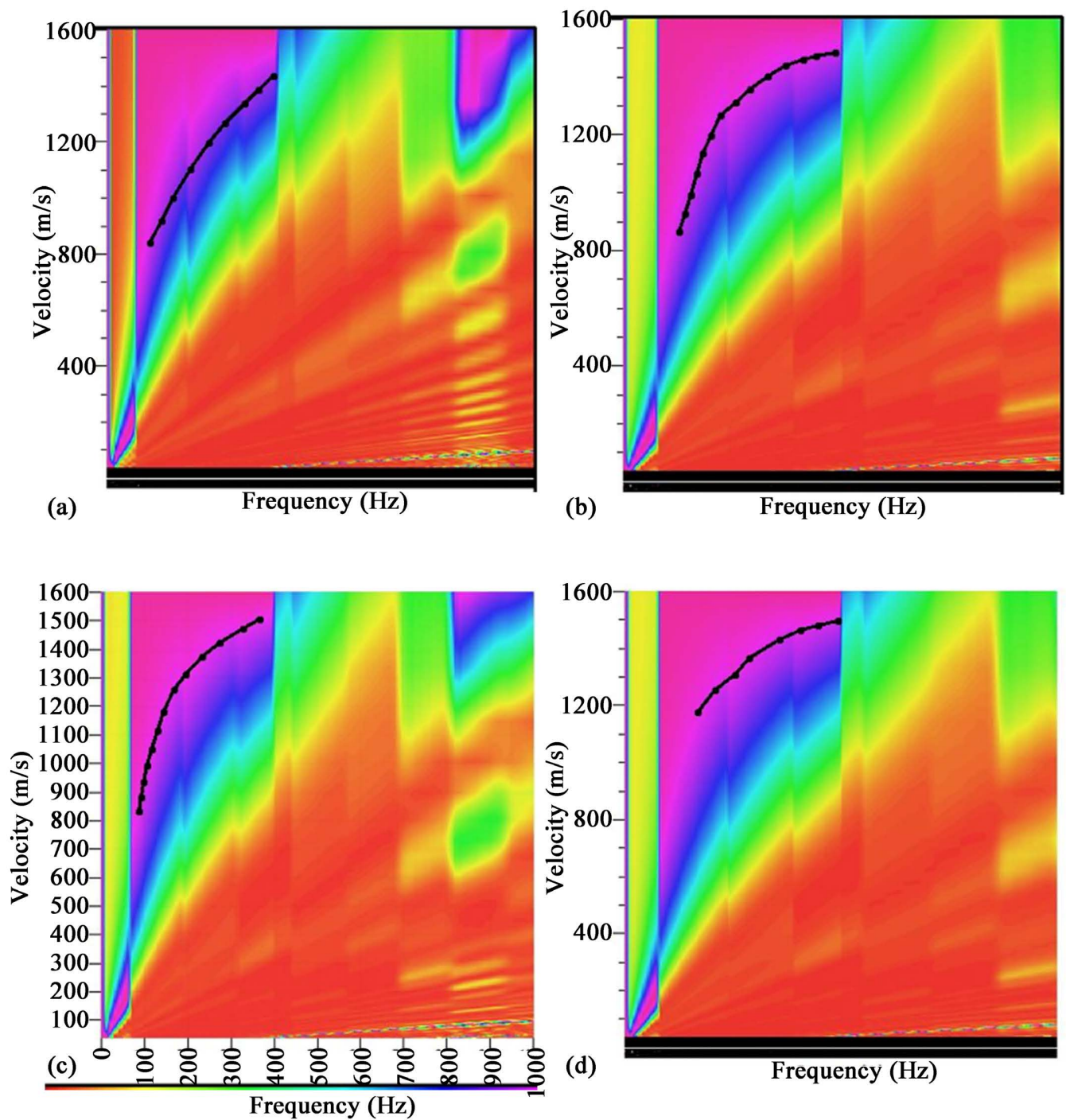

Figure 6. Dispersion curves and picking for test sites Auditorium (a), CNEPS (b), HLM (c) and Gendarmerie (d).

at the beginning, the dispersion curve shows the response of low frequencies. In the case where the depth layers reached rapidly by the low frequencies present high velocities, the dispersion curve appears at the beginning with high velocities. Otherwise, the dispersion curve starts with low velocities, which explains its reversal.

Velocity ranges show that the minimum rate of occurrence of the dispersion curve, reflecting the minimum velocity at the site studied, varies from site to site. The minimum velocities are 700, 600, 800 and $700 \mathrm{~m} / \mathrm{s}$ for Auditorium, CNEPS, Gendarmerie and HLM, respectively.

After picking the dispersion curve (Figure 6), the velocity/frequency data are exported to the Geopsy Dinver module to perform the inversion. Inversion begins with the choice of input parameters of the model based on a priori field knowledge [9]. On the HLM and Gendarmerie sites (3 and 4) the thicknesses of 
the first two layers are available which allowed us to fix them in the model Table 3.

The results obtained after the inverse modelling are shown in Figure 7.

Table 3. Model a priori parameters used for inversion.

\begin{tabular}{|c|c|c|c|c|c|}
\hline \multirow{2}{*}{ Site } & \multicolumn{3}{|c|}{ Parameters } & \multirow{2}{*}{$\mathbf{v}$} & \multirow{2}{*}{$\rho\left(\mathrm{kg} / \mathrm{m}^{3}\right)$} \\
\hline & $Z_{\mathrm{Top}}(\mathrm{m})$ & $V_{P}(\mathrm{~m} / \mathrm{s})$ & $V_{\mathcal{S}}(\mathrm{m} / \mathrm{s})$ & & \\
\hline \multirow{3}{*}{1 and 2} & $0.04-0.08$ & $500-5000$ & $400-4000$ & \multirow{3}{*}{$0.2-0.5$} & \multirow{3}{*}{2000} \\
\hline & $0.15-0.2$ & $400-4800$ & $300-3000$ & & \\
\hline & 0.2 - Infini & $300-4500$ & $150-2500$ & & \\
\hline \multirow{3}{*}{3 and 4} & 0.05 & $500-5000$ & $400-4000$ & & \\
\hline & 0.15 & $400-4800$ & $300-3000$ & & \\
\hline & 0.15 - Infini & $300-4500$ & $150-2500$ & & \\
\hline
\end{tabular}
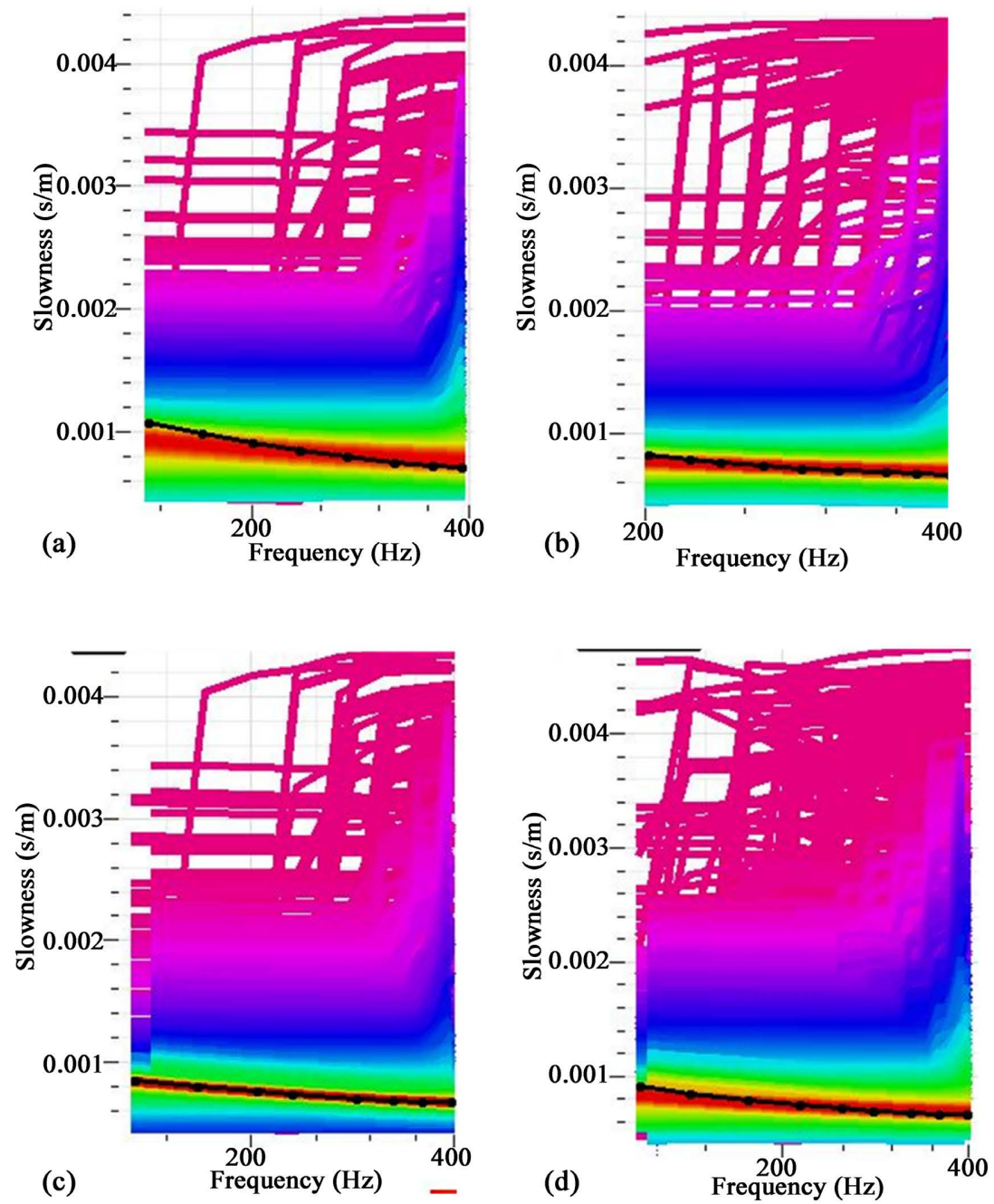

Figure 7. Overview of the superposition of the theoretical and experimental dispersion curves for the test sites Auditorium (a), CNEPS (b), HLM (c) and, Gendarmerie (d). 
The inversion quality, iteration number, convergence and misfit are available on log files. The inversion gives very low misfit values (less than 1) after a maximum number of iterations of 50. The correct superposition of the theoretical and experimental dispersion curves (Figure 7) confirms the quality of the model obtained after inversion

The velocity profiles for the different test sites are shown in Figure 8.

The obtained models, showing the variations $V_{P}$ and $V_{S}$ as a function of depth which have been interpreted according to the base of pavement layers are shown in Table 4.

The results confirm that the profile of $V_{S}$ is more accurate than that of $V_{P}$ that is to say that the minimum misfit values obtained in $V_{S}$ appearing on the red band are "narrower" and has a minimum uncertainty. The results confirmed also that velocity decreases with depth except for the foundation layer of Gendarmerie.

All the found results are consistent with approximate velocities of the different materials making up the pavement layers [31] [32] [33].

From these shear wave velocities $V_{S}$ compression $V_{P}$ the Poisson ratio $v$, and

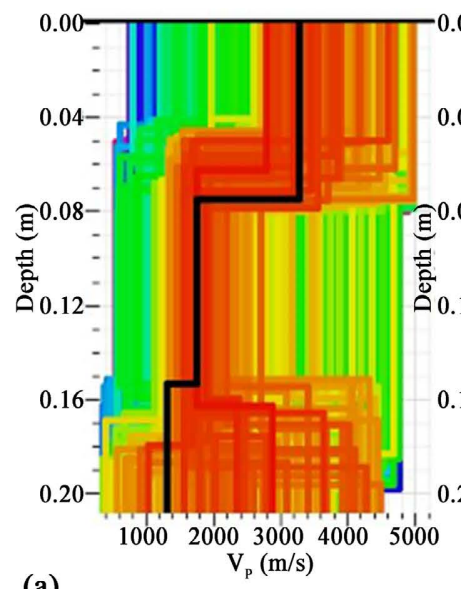

(a)

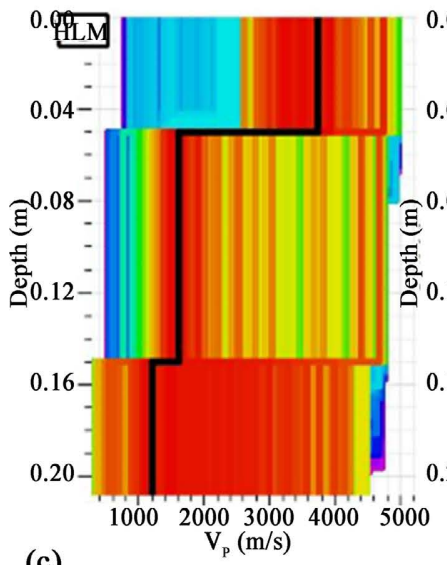

(c)

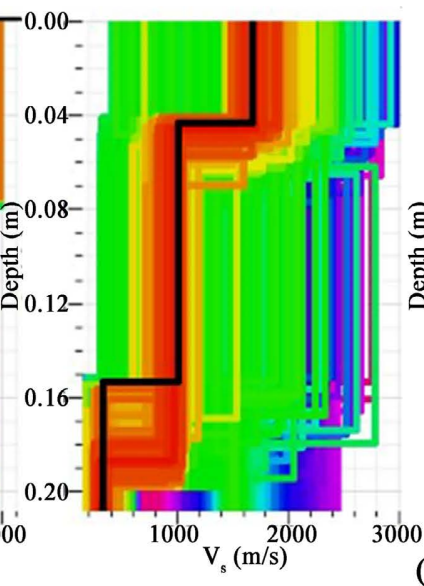

(b)
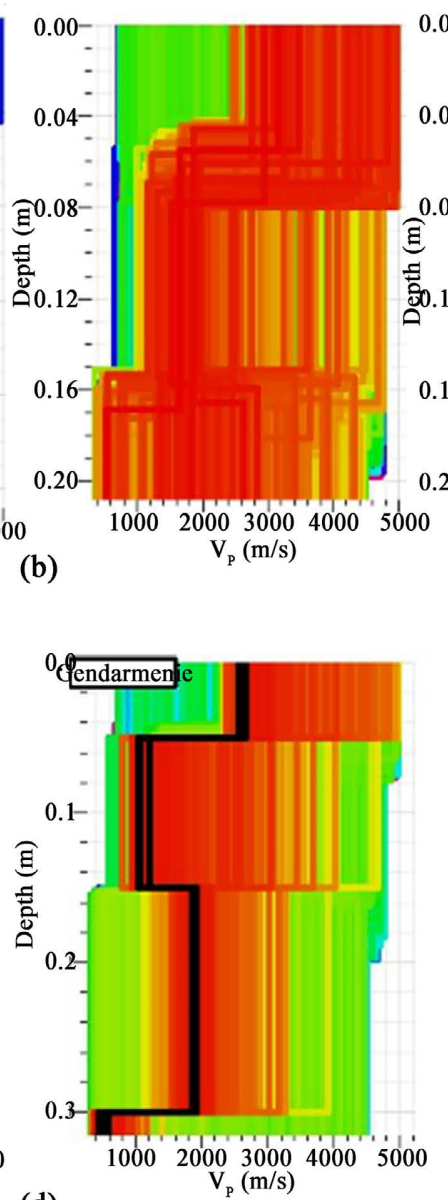

(d)
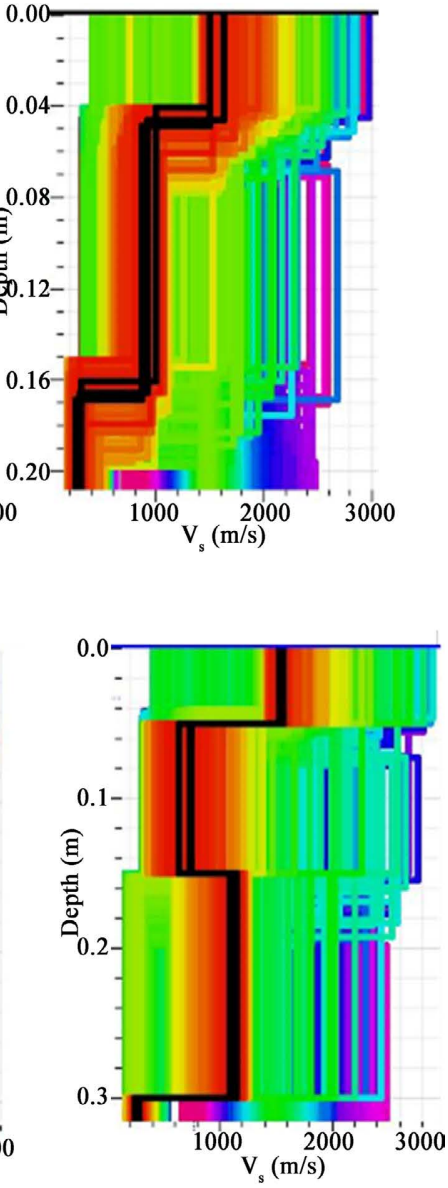

Figure 8. $V_{P}$ and $V_{S}$ profiles obtained after inversion for the test sites Auditorium (a), CNEPS (b), HLM (c) and Gendarmerie (d). The black curve in the middle of the red ones corresponds to the minimum misfit. 
Table 4. Results of the dispersion curve inversion for different test sites.

\begin{tabular}{ccccc}
\hline Site & Pavement layer & $Z(\mathrm{~m})$ & $V_{P}(\mathrm{~m} / \mathrm{s})$ & $V_{S}(\mathrm{~m} / \mathrm{s})$ \\
\hline Auditorium & Surface layer & 0.04 & 3400 & 1600 \\
& Base layer & 0.15 & 1800 & 1000 \\
& Foundation layer & - & 1300 & 550 \\
CNEPS & Surface layer & 0.05 & 1300 & 1600 \\
& Base layer & 0.16 & 3000 & 1000 \\
& Foundation layer & - & 2300 & 300 \\
HLM & Surface layer & 0.5 & 1600 & 1500 \\
& Base layer & 0.15 & 3700 & 900 \\
& Foundation layer & - & 1600 & 300 \\
& Surface layer & 0.20 & 5120 & 1200 \\
Gendarmerie & Base layer & 0.33 & 720 & 1920 \\
& Foundation layer & 0.17 & 2880 & 6729 \\
\hline
\end{tabular}

the density $\rho$ considered as constant due to its to small changes in the different pavement layers [34], it is possible to estimate the modulus values of the pavement layers according to the following formulas for Poisson ratio $v$, Shear modulus $G$, Young modulus $E$ respectively:

$$
\begin{gathered}
v=\frac{V_{P}^{2}-2 V_{S}^{2}}{2\left(V_{P}^{2}-V_{S}^{2}\right)} \\
G=V_{S}^{2} \times \rho \\
E=2 \rho V_{S}^{2}(1+v)
\end{gathered}
$$

The results of the calculations are recorded in Table 5.

Modules obtained at the level of the surface layers varying around 12,000 and $13,000 \mathrm{MPa}$ agrees well with the expected one because the corresponding material is bituminous concrete [34].

With regard to base and foundation layers, composed of compacted granular materials, the obtained modules are within the range of reversible module obtained at many studies [2].

\section{Conclusions}

The embedded MASW acquisition data built in this work, consisting of an Arduino microcontroller and Raspberry Pi makes it possible to avoid the difficulties related to the use of heavy seismograph in in service road investigation. In addition, the use of geophones without spike, operating in land-streamer mode has made data acquisition faster.

The device also makes it possible to accurately detect the moment of the 
Table 5. Obtained Elastic properties for the various test sites.

\begin{tabular}{ccccc}
\hline Site & Pavement layer & $\boldsymbol{V}$ & $\boldsymbol{G}(\mathrm{MPa})$ & $\boldsymbol{E}(\mathrm{MPa})$ \\
\hline Auditorium & Surface layer & 0.36 & 5120 & 13,904 \\
& Base layer & 0.28 & 2000 & 5107 \\
& Foundation layer & 0.39 & 605 & 1683 \\
CNEPS & Surface layer & 0.30 & 5120 & 13,325 \\
& Base layer & 0.38 & 2000 & 5534 \\
& Foundation layer & 0.48 & 180 & 533 \\
& Surface layer & 0.40 & 4500 & 12,615 \\
& Base layer & 0.27 & 1620 & 4110 \\
& Foundation layer & 0.47 & 180 & 528 \\
& Surface layer & 0.20 & 5120 & 12,239 \\
& Base layer & 0.33 & 720 & 1920 \\
& Foundation layer & 0.17 & 2880 & 6729 \\
\hline
\end{tabular}

source triggering, which is necessary for a precise measurement despite the very high velocity of the seismic waves.

Four tests conducted at the Auditorium, CNEPS, HLM and Gendarmerie sites show seismograms illustrating a phenomenon of reverse dispersion characteristic of pavement layers.

The measured surface wave velocities, dispersion analysis and the picking of dispersion curves were based on the results of several studies and showed that the fundamental mode has a rising trend with a phase velocity increasing as a function of frequency. The inversion of the dispersion curves with misfits inferior to $1 \%$, gave the relevant shear and compression velocity profiles based on the geometry of the pavement layers for each site. By exploiting the relationships between velocities and elastic proprieties, modules obtained at the level of the surface layers varying around 12,000 and 13,000 MPa agrees well with the expected one because the corresponding material is bituminous concrete.

In order to improve this light weight MASW acquisition system, it is subsequently envisaged to increase the number of geophones and automate their traction using a robot and to filter the high frequencies produced by Arduino DAC artifacts.

\section{Conflicts of Interest}

The authors declare no conflicts of interest regarding the publication of this paper.

\section{References}

[1] Scholz, T.V. and Rajendran, S. (2009) Investigating Premature Pavement Failure 
Due to Moisture (No. FHWA-OR-RD-10-02). Oregon Department of Transportation.

[2] Dione, A., et al. (2014) Implementation of Resilient Modulus-CBR Relationship in Mechanistic Pavement Design. Sciences Appliquées et de P Ingénieur, 1, 65-71.

[3] Levasseur, S. (2007) Analyse Inverse en Géotechnique: Développement d’une méthode à base d'algorithmes génétiques. Université Joseph-Fourier-Grenoble I, Grenoble.

[4] Sawangsuriya, A., Fall, M. and Fratta, D. (2008) Wave-Based Techniques for Evaluating Elastic Modulus and Poisson's Ratio of Laboratory Compacted Lateritic Soils. Geotechnical and Geological Engineering, 26, 567-578.

https://doi.org/10.1007/s10706-008-9190-7

[5] Locat, J. and Beauséjour, N. (1987) Corrélations entre des propriétés mécaniques dynamiques et statiques de sols argileux intacts et traités à la chaux. Canadian Geotechnical Journal, 24, 327-334. https://doi.org/10.1139/t87-043

[6] Foti, S., et al. (2014) Surface Wave Methods for Near-Surface Site Characterization. CRC Press, London. https://doi.org/10.1201/b17268

[7] Park, C.B., Miller, R.D. and Xia, J.H. (1998) Imaging Dispersion Curves of Surface Waves on Multi-Channel Record. SEG Technical Program Expanded Abstracts 1998, Society of Exploration Geophysicists, Tulsa, 1377-1380. https://doi.org/10.1190/1.1820161

[8] Kennett, B.L.N. and Kerry, N.J. (1979) Seismic Waves in a Stratified Half Space. Geophysical Journal International, 57, 557-583. https://doi.org/10.1111/j.1365-246X.1979.tb06779.x

[9] Ólafsdóttir, E.Á. (2016) Multichannel Analysis of Surface Waves for Assessing Soil Stiffness. University of Iceland, Reykjavík.

[10] Ryden, N. (2009) Surface Wave Testing of Pavements. The Journal of the Acoustical Society of America, 125, 2603. https://doi.org/10.1121/1.4783908

[11] Suto, K. and Kristinof, R. (2014) An MASW Survey to Assess Flood Damaged Road-A Case History. 27 th Annual Symposium on the Application of Geophysics to Engineering and Environmental Problems (SAGEEP), Boston, 16-20 March 2014, 406-411. https://doi.org/10.4133/SAGEEP.27-143

[12] Heymann, G. (2007) Ground Stiffness Measurement by the Continuous Surface Wave Test. Journal of the South African Institution of Civil Engineering, 49, 25-31.

[13] Al-Hunaidi, M.O. (1993) Insights on the SASW Nondestructive Testing Method. Canadian Journal of Civil Engineering, 20, 940-950. https://doi.org/10.1139/193-126

[14] Park, C., et al. (2018) MASW Applications for Road Construction and Maintenance. The Leading Edge, 37, 714-792. https://doi.org/10.1190/tle37100724.1

[15] Lin, S.B. and Ashlock, J.C. (2015) Comparison of MASW and MSOR for Surface Wave Testing of Pavements. Journal of Environmental and Engineering Geophysics, 20, 277-285. https://doi.org/10.2113/JEEG20.4.277

[16] Caprioli, P. (1991) Auscultation structurale des sols et des chaussées routières à partir de la propagation d'ondes mécaniques totalement et partiellement guidées. These de Doctorat, Université Louis-Pasteur, Strasbourg.

[17] Park, C., et al. (2004) Imaging Dispersion Curves of Passive Surface Waves. SEG Technical Program Expanded Abstracts, 1357-1360.

https://doi.org/10.1190/1.1851112

[18] Louie, J.N. (2001) Faster, Better: Shear-Wave Velocity to 100 Meters Depth from Refraction Microtremor Arrays. Bulletin of the Seismological Society of America, 
91, 347-364. https://doi.org/10.1785/0120000098

[19] Sanchez-Salinero, I., et al. (1987) Analytical Evaluation of Variables Affecting Surface Wave Testing of Pavements. Transportation Research Record, 1136.

[20] Yuan, J.B., Zhu, J.Y. and Kim, C.Y. (2014) Comparison of SASW and MASW Methods Using MSOR Approach-A Case Study. International Journal of Geotechnical Engineering, 8, 233-238. https://doi.org/10.1179/1938636213Z.00000000077

[21] Ayolabi, E.A. and Adegbola, R.B. (2014) Application of MASW in Road Failure Investigation. Arabian Journal of Geosciences, 7, 4335-4341.

https://doi.org/10.1007/s12517-013-1078-z

[22] Park, C.B. and Carnevale, M. (2010) Optimum MASW Survey-Revisit after a Decade of Use. GeoFlorida 2010: Advances in Analysis, Modeling \& Design, Orlando, 20-24 February 2010, 1303-1312. https://doi.org/10.1061/41095(365)130

[23] Hassaim, M., et al. (2001) Évaluation de l'état du béton par la technique d'analyse spectrale des ondes de Rayleigh. Canadian Journal of Civil Engineering, 28, 1018-1028. https://doi.org/10.1139/101-062

[24] Yang, Z.T., et al. (2019) Multi-Channel Analysis of Rayleigh Waves Based on Vector Wavenumber Tansformation Method (VWTM). Chinese Journal of Geophysics, 62 , 298-305.

[25] Due, A. and Core, A.R.M. (2017) Arduino Due. Retrieved, 9, 2019.

[26] Atiqur, R. and Li, Y. (2020) Automated Smart Car Parking System Using Raspberry Pi 4 and iOS Application. International Journal of Reconfigurable and Embeded Systems (IJRES), 9, 229-234. https://doi.org/10.11591/ijres.v9.i3.pp229-234

[27] Vitale, G., et al. (2018) Bandwidth Extension of a $4.5 \mathrm{~Hz}$ Geophone for Seismic Monitoring Purpose. 2018 IEEE International Conference on Environmental Engineering, Milan, 12-14 March 2018, 1-5. https://doi.org/10.1109/EE1.2018.8385253

[28] Van der Veen, M., Spitzer, R., Green, A.G. and Wild, P. (2001) Design and Application of a Towed Land-Streamer System for Cost-Effective 2-D and Pseudo-3-D Shallow Seismic Data Acquisition. Geophysics, 66, 482-500. https://doi.org/10.1190/1.1444939

[29] Beyreuther, M., et al. (2010) ObsPy: A Python Toolbox for Seismology. Seismological Research Letters, 81, 530-533. https://doi.org/10.1785/gssrl.81.3.530

[30] Wathelet, M., et al. (2020) Geopsy: A User-Friendly Open-Source Tool Set for Ambient Vibration Processing. Seismological Research Letters, 91, 1878-1889. https://doi.org/10.1785/0220190360

[31] Arulrajah, A., Piratheepan, J. and Disfani, M.M. (2014) Reclaimed Asphalt Pavement and Recycled Concrete Aggregate Blends in Pavement Subbases: Laboratory and Field Evaluation. Journal of Materials in Civil Engineering, 26, 349-357. https://doi.org/10.1061/(ASCE)MT.1943-5533.0000850

[32] Gorski, M. (2000) Determination des Modules de Couches de Chaussees Bitumineuses A Partir des Mesures de Portance et d'Epaisseur (Curviametre et Radar). Bulletin CRR/ OCW Mededelingen, 42.

[33] Suarez, C.A.M. (2010) Estimation du module réversible des matériaux granulaires de chaussées. Université Laval, Québec.

[34] Ebrahim, R., et al. Etude de la variation du module complexe des enrobés bitumineux sous chargement cyclique. Academic Journal of Civil Engineering, 34, 858-865. 